\title{
Side-effects of antituberculosis drug treatment in patients with chronic renal failure
}

\author{
S.J. Quantrill*, M.A. Woodhead*, C.E. Bell*, C.C. Hardy*, A.J. Hutchison", R. Gokal ${ }^{\#}$
}

Side-effects of antituberculosis drug treatment in patients with chronic renal failure. S.J. Quantrill, M.A. Woodhead, C.E. Bell, C.C. Hardy, A.J. Hutchison, R. Gokal. (C) ERS Journals Ltd 2002.

ABSTRACT: Patients with chronic renal failure (CRF) have a high incidence of tuberculosis (TB). Those from the Indian subcontinent are at particular risk. The frequency of side-effects associated with antituberculous treatment in a group of patients with CRF was studied.

All cases of TB in patients with CRF occurring over a 13-yr period at the Manchester Royal Infirmary, from 1986-1999, were identified by diagnostic coding, microbiology records and a TB database. The case notes were then reviewed.

Twenty-four cases were identified, eight predialysis and 16 requiring regular dialysis. TB occurring in the dialysis group was extrapulmonary in every case. Nineteen of 24 $(79 \%)$ patients were of Indian subcontinent origin and 14 of $16(87 \%)$ dialysis patients were non-Caucasian. Adverse effects of treatment occurred in two of eight $(25 \%)$ in the predialysis group and nine of $16(56 \%)$ of the dialysis group. These were most commonly neuropsychiatric (6), hepatic (4) and gastrointestinal (4). Neuropsychiatric symptoms occurred exclusively in dialysis patients.

In conclusion, a high incidence of side-effects from antituberculous medication, especially neuropsychiatric, hepatic and gastrointestinal, was identified in patients with chronic renal failure. Careful monitoring for side-effects is essential in this group, and consideration should be given to administering antituberculous chemoprophylaxis to all high-risk groups.

Eur Respir J 2002; 20: 440-443.
* Depts of Respiratory Medicine and ${ }^{\#}$ Renal Medicine, Manchester Royal Infirmary, Manchester, UK.

Correspondence: S. Quantrill

Dept of Cystic Fibrosis

Royal Brompton Hospital

Sydney Street

London

SW3 6NP

UK

Fax: 442073518052

E-mail: s.quantrill@ic.ac.uk

Keywords: Chronic renal failure dialysis

side-effects

tuberculosis

Received: November 272001

Accepted after revision: February 6 2002
Patients with chronic renal failure (CRF) have a high incidence of tuberculosis (TB), possibly due to a decrease in cellular immunity [1-4]. Treatment of TB in CRF may be complicated by an increased risk of toxicity from antituberculous drugs, particularly isoniazid and ethambutol. Current British Thoracic Society (BTS) guidelines lack explicit recommendations for the management of these patients [5].

The Manchester Royal Infirmary (MRI) has a large renal unit with dialysis facilities and a catchment population that includes a high proportion of nonCaucasians, especially from the Indian subcontinent. In this study, all cases of TB occurring in patients with pre-existing CRF over a 13-yr period at the MRI were reviewed.

\section{Methods}

CRF can be defined as an irreversible deterioration of kidney function occurring usually over a period of years. Between 1986-1999, cases of TB in patients with CRF were identified by three methods: medical out-patient coding, microbiology records and the respiratory department TB database. For the purpose of this study, a case of TB was considered to be any patient receiving a course of antituberculous chemotherapy, regardless of whether the diagnosis was based on clinical suspicion or microbiological results. Adverse effects were defined as symptoms and/ or signs thought to be due to antituberculous treatment and of sufficiently serious or severe nature to warrant an alteration in therapy. Patients' case notes were then inspected and relevant data recorded. All patients were treated at the same institution (MRI) for both CRF and TB.

\section{Results}

Twenty-four cases were identified, of which eight were predialysis and 16 were on regular dialysis (14 continuous ambulatory peritoneal dialysis (CAPD), two haemodialysis). Sex distribution was equal and the age range was 26-73 yrs (median 53 yrs).

The most common sites affected were the peritoneum, lymph nodes, lung and pleura (table 1). More than one site was involved in three patients. In the dialysis group, all cases were extrapulmonary in origin. The most common symptoms were fever and weight loss, but most patients had a combination of nonspecific complaints. Chest radiography was normal in 10 patients and did not reveal cavitation in any cases (table 1). 
Table 1. - Site of tuberculosis (TB) and chest radiograph appearance

\begin{tabular}{lcc}
\hline & $\begin{array}{c}\text { Patients } \\
\text { predialysis } \mathrm{n}\end{array}$ & $\begin{array}{c}\text { Patients } \\
\text { dialysis } \mathrm{n}\end{array}$ \\
\hline Total & 8 & 16 \\
Site of TB & 0 & 8 \\
$\quad$ Peritoneum & 0 & 6 \\
Lymph node & 2 & 2 \\
Pleura & 4 & 0 \\
Pulmonary & 2 & 0 \\
Bone & 0 & 1 \\
Cryptic & 1 & 0 \\
Thigh & 0 & 1 \\
Ankle & & \\
Chest radiograph & & 10 \\
appearance & 1 & 5 \\
Normal & 2 & 1 \\
Pleural effusion & 4 & 1 \\
Consolidation & 1 & 1 \\
Lymphadenopathy & 0 & 0 \\
Nodules & 1 & 1 \\
Old TB & 0 & \\
Cardiomegaly & & \\
\hline
\end{tabular}

Most patients were from the Indian subcontinent, especially Pakistan, and only three were Caucasian (table 2). One in $11(9 \%)$ of Asian patients commencing dialysis subsequently developed TB. No patients had any previous history of mycobacterial infection, whilst six gave a positive family history of TB. The primary renal disease in most cases was unknown. Diabetes mellitus was present in five. None were known to be infected with human immunodeficiency virus. Two patients were on regular oral corticosteroid therapy following a previous failed renal transplant $\left(9 \mathrm{mg} \cdot \mathrm{day}^{-1}\right)$ and crescentic glomerulonephritis $\left(5 \mathrm{mg} \cdot \mathrm{day}^{-1}\right)$.

Sixteen of $24(67 \%)$ cases were culture positive, of which six were smear positive. Mycobacterium tuberculosis was isolated in all 16 culture-positive cases. Resistance occurred in one instance (to isoniazid).
Histology, showing typical granulomata strongly suggestive of $\mathrm{TB}$, was present in 11 cases and was the main diagnostic investigation in five of these. Two cases were diagnosed on clinical grounds plus a response to therapy. Tuberculin testing was not performed on any of the patients.

Treatment was usually undertaken with a standard combination and doses of rifampicin, isoniazid and pyrazinamide, as per the BTS Guidelines [5], and was administered for 6-18 months in total. The dose of isoniazid had been reduced in three cases, to $200 \mathrm{mg}$ daily in two and $100 \mathrm{mg}$ daily in another. Ethambutol was prescribed in seven cases. Pyridoxine was usually prescribed at a dose of $10 \mathrm{mg} \cdot \mathrm{day}^{-1}$.

Side-effects of treatment that were sufficient to alter therapy were noted in 11 of $24(46 \%)$ patients (two predialysis, nine dialysis) and included a high incidence of neuropsychiatric problems, which occurred exclusively in the dialysis group (six of 16 $(37 \%)$ dialysis patients (table 2$)$ ). Jaundice and gastrointestinal symptoms were also relatively common, with each occurring in four of $16(25 \%)$ dialysis patients.

Those patients with neuropsychiatric symptoms were all receiving pyridoxine and three were taking a reduced dose of isoniazid. The three patients suffering grand mal seizures each had normal computed tomography brain scans and, in two cases, normal lumbar punctures (table 2). Treatment was stopped in each case and recommenced after a period of 2-4 weeks. Isoniazid was continued after this time in the same dose in all but patient number 11 (in which it was stopped). Patient number 6 suffered a relapse of side-effects after restarting treatment, but was nevertheless able to continue. Patient number 3 was readmitted 2 months later with a reduced level of consciousness requiring mechanical ventilation; an electroencephalogram (EEG) was suggestive of temporal lobe status epilepticus. None of these patients had any prior history of seizures.

Only one death that could be attributed to TB

Table 2. - Side-effects of treatment

\begin{tabular}{|c|c|c|c|c|c|c|c|}
\hline $\begin{array}{l}\text { Patient } \\
\text { no. }\end{array}$ & $\begin{array}{l}\text { Stage of } \\
\text { renal failure }\end{array}$ & $\begin{array}{l}\text { Age } \\
\text { yrs }\end{array}$ & Ethnicity & $\begin{array}{l}\text { Anti-TB } \\
\text { treatment }\end{array}$ & $\begin{array}{l}\text { Dose of } \\
\text { isoniazid } \\
\text { mg daily }\end{array}$ & Side-effects of treatment & $\begin{array}{l}\text { Time from start } \\
\text { of treatment } \\
\text { weeks }\end{array}$ \\
\hline 1 & Predialysis & 65 & $\mathrm{C}$ & RHZ & 300 & Jaundice & 2 \\
\hline 2 & Predialysis & 35 & ISC & RHZ & 300 & Anorexia, nausea, vomiting & 2 \\
\hline 3 & CAPD & 26 & ISC & RHZ & 300 & Jaundice, confusion, grand mal seizures & 3 \\
\hline 4 & CAPD & 28 & $\mathrm{BA}$ & RH & 200 & $\begin{array}{l}\text { Jaundice, nausea, vomiting, dizziness, } \\
\text { acute depressive psychosis }\end{array}$ & 9 \\
\hline 5 & CAPD & 36 & ISC & RH & 300 & Jaundice & 2 \\
\hline 6 & CAPD & 46 & ISC & RHZE & 300 & $\begin{array}{l}\text { Nausea, vomiting, dizziness, nightmares, } \\
\text { hallucinations, peripheral neuropathy }\end{array}$ & 3 \\
\hline 7 & CAPD & 50 & $\mathrm{C}$ & RHZ & 100 & Headaches, grand mal seizures & 8 \\
\hline 8 & CAPD & 59 & ISC & RHZ & 300 & $\begin{array}{l}\text { Vomiting, diarrhoea, confusion, } \\
\text { drowsiness, twitching }\end{array}$ & 2 \\
\hline 9 & CAPD & 34 & ISC & RHZE & 300 & Dizziness & 1 \\
\hline 10 & CAPD & 63 & ISC & RHZ & 300 & Drug-fever & 2 \\
\hline 11 & HD & 53 & ISC & RHZ & 200 & Confusion, grand mal seizure & 4 \\
\hline
\end{tabular}

CAPD: continuous ambulatory peritoneal dialysis; HD: haemodialysis; C: Caucasian; ISC: Indian subcontinent; BA: Black African; R: rifampicin; H: isoniazid; Z: pyrazinamide; E: ethambutol. 
occurred, from acute small bowel obstruction secondary to adhesions due to peritoneal TB.

\section{Discussion}

A high incidence of side-effects associated with antituberculous drug treatment in patients with chronic renal failure was found, occurring in 11 of $24(46 \%)$ patients overall and nine of $16(56 \%)$ dialysis patients. This resulted in a change in antituberculous medication in most cases and is in marked contrast with both the current authors' experience and the published data in patients with normal renal function. Data over the past 4 yrs from the authors own TB database reveals that of 225 patients with normal renal function, $58(26 \%)$ were recorded as having sideeffects, but only $11(5 \%)$ had side-effects sufficient to change treatment. This is in keeping with a previous large study, in which $5.1 \%$ had drug reactions serious enough to warrant modification of treatment [6].

The most prominent finding was that a large proportion of the dialysis group suffered neuropsychiatric symptoms, including grand mal seizures in three cases, in addition to various psychotic phenomena such as nightmares, hallucinations and confusion. Although the authors cannot prove beyond doubt that these symptoms occurred as a result of antituberculous, specifically isoniazid therapy, a number of factors point to this conclusion. Firstly, there was a strong temporal association between commencing isoniazid and the development of sideeffects (2-9 weeks). Secondly, the patients in this study had not previously been known to suffer from any such central nervous system problems, and other major causes were eliminated as far as possible. Thirdly, such side-effects have been documented in relation to isoniazid use in dialysis patients [7-9]. Hepatitis, resulting in jaundice, also occurred more frequently than expected, in four cases: three of these were aged 26, 28 and 36 yrs. In this age group, the usual incidence of this side-effect of antituberculous chemotherapy is only $1.8 \%$ [6].

The patients in this study could be categorised into two separate groups, namely predialysis and dialysis, as the clinical characteristics and treatment problems were different in each. Those in the dialysis group had a much higher incidence of extrapulmonary TB and side-effects of treatment. Most studies have shown a predominance of extrapulmonary $\mathrm{TB}$ in dialysis patients [10-12] and this was also the case in this series. Peritoneal TB, otherwise relatively uncommon and which occurred in eight of $14(57 \%)$ of the CAPD patients in this study, is the subject of a separate paper [13]. The other main extrapulmonary site was lymph nodes that were affected in six patients, all on dialysis. Chest radiography was largely unhelpful in diagnosis, in most cases being normal or revealing small pleural effusions, which are a common finding in CRF, especially in dialysis patients.

Current BTS guidelines make no separate recommendation for patients with TB who are undergoing regular dialysis [5]. Although a dose reduction of isoniazid has been advocated [14], this may be unnecessary and result in subtherapeutic levels [15, 16]. Isoniazid, pyrazinamide and rifampicin should be used in standard doses since metabolism is predominantly hepatic and acetylation status largely irrelevant [17]. In a recent survey of UK renal units, however, the current authors found that the dose of isoniazid used varied from $100-300 \mathrm{mg} \cdot \mathrm{day}^{-1}$ and sometimes varied according to body weight [18]. The dose of pyridoxine also varied from 10 to $50 \mathrm{mg} \cdot \mathrm{day}^{-1}$. Pyridoxine in a dose of $100 \mathrm{mg} \cdot \mathrm{day}^{-1}$ has been recommended to prevent neurological side effects of isoniazid [9], but this relatively high dose may be antagonistic to isoniazid itself, resulting in reduced antituberculous efficacy [19].

One solution to the problem of $\mathrm{TB}$ in dialysis patients may be to give antituberculous chemoprophylaxis to all high risk patients (e.g. those from certain ethnic groups) commencing CAPD or haemodialysis. Indeed, this has already been advocated by some workers and treatment may only need to be given for 6-12 months in total [1, 20-22]. Since 14 of $16(87 \%)$ of the patients in this study were of nonCaucasian origin, this strongly suggests that only nonCaucasians would need chemoprophylaxis. Isoniazid can be used, but again side-effects are a possibility $[8,9]$ and alternative regimens might be considered such as rifampicin with or without pyrazinamide [22].

The occurrence of TB in a patient with CRF is unlikely to be common in most UK centres. However, the current authors feel that the BTS guidelines should emphasise the need for standard antituberculous chemotherapy for such patients, but should also emphasise the need for additional close monitoring in this group because of the high incidence of significant treatment side-effects. Consideration should be given to administering 6 months' chemoprophylaxis to all Asian patients commencing dialysis.

In conclusion, a very high frequency of serious adverse effects from antituberculous treatment in patients with chronic renal failure has been found. Neuropsychiatric, hepatic and gastrointestinal sideeffects occurred most frequently.

\section{References}

1. Cuss FMC, Carmichael DJS, Linington A, Hulme B. Tuberculosis in renal failure: a high incidence in patients born in the third world. Clin Nephrol 1986; 25: 129-133.

2. Andrew GT, Schoenfeld PY, Hopewell PC, Humphreys $\mathrm{MH}$. Tuberculosis in patients with endstage renal disease. Am J Med 1980; 68: 59-65.

3. Cengiz K. Increased incidence of tuberculosis in patients undergoing haemodialysis. Nephron 1996; 73: 421-424

4. Newberry WM, Sanford JP. Defective cellular immunity in renal failure: depression of reactivity of lymphocytes to phytohemagglutinin by renal failure serum. J Clin Invest 1971; 50: 1262-1271.

5. Joint Tuberculosis Committee of the British Thoracic Society. Chemotherapy and management of tuberculosis in the United Kingdom: recommendations. Thorax 1998; 53: 536-548.

6. Ormerod LP, Horsfield N. Frequency and type of 
reactions to antituberculosis drugs: observations in routine treatment. Tuber Lung Dis 1996; 77: 3742.

7. Cheung WC, Lo CY, Lo WK, Ip M, Cheng IKP. Isoniazid induced encephalopathy in dialysis patients. Tuber Lung Dis 1993; 74: 136-139.

8. Asnis DS, Bhat JG, Melchert AF. Reversible seizures and mental status changes in a dialysis patient on isoniazid preventative therapy. Ann Pharm 1993; 27: 444446.

9. Siskind MS, Thienemann D, Kirlin L. Isoniazidinduced neurotoxicity in chronic dialysis patients: report of three cases and a review of the literature. Nephron 1993; 64: 303-306.

10. Malhotra KK, Parashar MK, Sharma RK, Bhuyan UN, Dash SC, Kumar R. Tuberculosis in maintenance hemodialysis patients. Study from an endemic area. Postgrad Med J 1981; 57: 492-498.

11. Hussein MM, Bakir N, Roujouleh H. Tuberculosis in patients undergoing maintenance dialysis. Nephrol Dial Transplant 1990; 5: 584-587.

12. Rutsky EA, Rostand SG. Mycobacteriosis in patients with chronic renal failure. Arch Intern Med 1980; 140: 57-61.

13. Quantrill SJ, Woodhead MA, Bell CE, Hutchison AJ, Gokal R. Peritoneal tuberculosis in patients receiving continuous ambulatory peritoneal dialysis. Nephrol Dial Transplant 2001; 16: 1024-1027.

14. Tuberculosis in patients having dialysis (editorial). BMJ 1980; 349 .

15. Mitchison DA, Ellard GA. Tuberculosis in patients having dialysis. BMJ 1980; 280: 1186.

16. Mitchison DA, Ellard GA. Tuberculosis in patients having dialysis. BMJ 1980; 280: 1533.

17. Ellard GA. Chemotherapy of tuberculosis for patients with renal impairment. Nephron 1993; 64: 169-181.

18. Quantrill SJ, Woodhead MA. A survey of tuberculosis management policies in UK renal units. Thorax 1999; 54: S3-A51.

19. McCune R, Deuschle K, McDermott W. Delayed appearance of isoniazid antagonism by pyridoxine in vivo. Am Rev Tuberc Pulm Dis 1957; 76: 1100.

20. Kwan JTC, Hart PD, Raftery MJ, Cunningham J, Marsh FP. Mycobacterial infection is an important infective complication in British dialysis patients. J Hosp Inf 1991; 19: 249-255.

21. Isoniazid prevention of tuberculosis (editorial). Lancet 1983; 19: 395-396.

22. Korzets A, Gafter U. Tuberculosis prophylaxis for the chronically dialysed patient - yes or no? Nephrol Dial Transplant 1999; 14: 2857-2859. 